\title{
Comparing In Vitro and In Vivo Genomic Profiles Specific to Liver Toxicity Induced by Thioacetamide
}

\author{
Jin Seok Kang, Youn Kyoung Jeong, Ji He Shin, Soo Kyung Suh, Joo Hwan Kim, \\ Eun Mi Lee, Seung Hee KIM and Sue Nie PARK \\ Department of Toxicological Researches, National Institute of Toxicological Research, \\ Korea Food and Drug Administration, 194 Tongil-ro, Eunpyeong-gu, Seoul 122-704, Korea
}

(Received September 12, 2007/Accepted December 13, 2007)

\begin{abstract}
As it is needed to assay possible feasibility of extrapolation between in vivo and in vitro systems and to develop a new in vitro method for toxicity testing, we investigated global gene expression from both animal and cell line treated with thioacetamide (TAA) and compared between in vivo and in vitro genomic profiles. For in vivo study, mice were orally treated with TAA and sacrificed at 6 and $24 \mathrm{~h}$. For in vitro study, TAA was administered to a mouse hepatic cell line, BNL CL.2 and sampling was carried out at 6 and 24 h. Hepatotoxicity was assessed by analyzing hepatic enzymes and histopathological examination (in vivo) or lactate dehydrogenase (LDH) assay and morphological examination (in vitro). Global gene expression was assessed using microarray. In high dose TAA-treated group, there was centrilobular necrosis (in vivo) and cellular toxicity with an elevation of $\mathrm{LDH}$ (in vitro) at $24 \mathrm{~h}$. Statistical analysis of global gene expression identified that there were similar numbers of altered genes found between in vivo and in vitro at each time points. Pathway analysis identified several common pathways existed between in vivo and in vitro system such as glutathione metabolism, bile acid biosynthesis, nitrogen metabolism, butanoate metabolism for hepatotoxicty caused by TAA. Our results suggest it may be feasible to develop toxicogenomics biomarkers by comparing in vivo and in vitro genomic profiles specific to TAA for application to prediction of liver toxicity.
\end{abstract}

Keywords $\square$ thioacetamide, in vivo, in vitro, toxicogenomics, hepatotoxicity, microarray

\section{INTRODUCTION}

It is needed to develop new technologies to evaluate them more quickly and accurately not only for safety concern but also for cost-effectiveness, owing to occurrence of many new foods, drugs and chemicals. Among them, toxicogenomic approaches employing microarray technology allows to investigate expressions of thousands of genes affected simultaneously in biological experiment such as chemicalinduced toxicity test, and may serve as a valuable tool to evaluate new food and drugs. Toxicogenomics combines transcript, protein and metabolite profiling with conventional toxicology (Waters and Fostel 2004), and its approach should help not only to discover highly sensitive and predictive biomarkers for toxicity but also to understand molecular cellular mechanism of toxicity, including the fields of hepatotoxicity,

\footnotetext{
*Corresponding author

Tel: +82-2-380-1792, Fax: +82-2-388-6453

E-mail: suenie@kfda.go.kr
}

nephrotoxicity and genotoxicity (Pennie et al. 2004).

It is expected that it will compensate evaluation of toxicity measured by conventional ways, and it seems that toxicogenomics will provide powerful tool that may show gene and protein changes earlier, even at treatment levels below the limits of detection of traditional measures of toxicity, and it may be possible to apply toxicogenomics data into regulatory decision making (Boverhof and Zacharewski 2006) after biologic validation of toxicogenomics-based test methods (Corvi et al. 2006) and reviewing and analyzing toxicogenomics data (Leighton et al. 2006).

Thioacetamide (TAA) induced liver cell damage, fibrosis and/or cirrhosis, associated with increase of oxidative stress and activation of hepatic stellate cells (Kang et al. 2005; Li et al. 2002; Muller et al. 1988; Porter et al. 1979). It was metabolized via CYP450, and induced hepatocellular toxicities including hepatic cell necrosis (James et al. 2003; Porter et al. 1979).

Even though it seems that compounds with similar toxic mechanisms produce similar changes in gene expression in vivo and in vitro system (Waring et al. 2001a), there was also 
discrepancy for gene expressions between animal and cell line system (Perkins et al. 2006). Therefore it may be worthwhile to compare transcriptional responses in livers of animals and hepatocyte cells line after exposure to chemicals to determine how faithfully in vitro model system reflects in vivo responses using microarray.

In this study, we investigated global gene expression from both mouse liver and mouse hepatic cell line treated with TAA to gain a better understanding of molecular mechanisms. And we further compared between in vivo and in vitro profiles, and assessed the feasibility of the extrapolation between two systems to compare of in vitro gene expression profiles to in vivo system.

\section{MATERIALS AND METHODS}

\section{Materials}

Dulbecco's modified Eagle's medium (DMEM), fetal bovine serum (FBS) and penicillin-streptomycin were purchased from Invitrogen (Carlsbad, CA). CellTiter 96 Aqueous Non-Radioactive Cell Proliferation Assay kit was obtained from Promega Co. (Madison, WI) while cytotoxicity detection kit was from Roche Molecular Biochemicals (Indianapolis, IN). Mouse Genome Survey Microarray gene chips were supplied by Applied Biosystems (Foster City, CA). This microarray platform has 33,012 probes, which are 60 -mers, lie mostly within 1,500 base pairs of the 3' end of the source transcript. TAA was obtained from Sigma (St. Louis, MO).

\section{Animals and chemicals treatment}

In vivo experiment, male 5-week old ICR mice were supplied by the Department of Laboratory Animal Resources, the National Institute of Toxicological Research, Food and Drug Administration, Seoul, Korea. The animals were housed in polycarbonated cages with hardwood chips in a room with 12/ $12 \mathrm{~h}$ light/dark cycles and controlled humidity and temperature. They were allowed free access to pellet chow during the experiment. All procedures were approved by the Institutional Animal Care and Use Committee of National Institute of Toxicological Research.

Six-week-old mice $(n=32)$ were randomly allocated to four groups as follow: groups 1 as control, group 2 as vehicle (saline), groups 3 and 4 as TAA low and high dose treatment $(20,200 \mathrm{mg} / \mathrm{kg}$, respectively, dissolved in saline, i.p.). Mice were sacrificed at 6 and $24 \mathrm{~h}$ after the treatment.

Initial and final body weights were measured. At the end of the experiment, all animals were fasted overnight and euthanized by exsanguination under ether anesthesia. Blood was taken from the abdominal aorta, and serum biochemistry was performed for the following parameters: aspartate aminotransferase (AST), alanine aminotransferase (ALT), lactate dehydrogenase (LDH) and alkaline phosphatase (ALP) using Prestige 24i (Tokyo Boeki Medical System, Japan).

At necropsy, half of livers were fixed in 10\% phosphatebuffered formalin, and routinely processed for embedding in paraffin, and staining of $4 \mu \mathrm{m}$ sections with hematoxylin and eosin for histopathological examination. And the remaining samples from all the animals were snap-frozen in liquid nitrogen for RNA extraction and subsequent analysis.

\section{Cell line, cell culture and chemicals treatment}

In vitro experiment, murine embryonic normal hepatic cell line, BNL CL.2 cells (ATCC TIB-73) was purchased from American Type Culture Collection (Manassas, VA). The cells were cultured in DMEM medium supplemented with 100 units of penicillin-streptomycin, $2 \mathrm{mM}$ L-glutamine, and 10\% FBS at $37^{\circ} \mathrm{C}$ in a $5 \% \mathrm{CO}_{2}$ atmosphere.

TAA was dissolved in dimethyl sulfoxide (DMSO) and were freshly diluted in culture media for each experiment. Vehicle concentrations were less than $0.5 \%$ in all experiments. At 6 or $24 \mathrm{~h}$ after treatment, cells were harvested for RNA extraction.

\section{Cytotoxicity assay}

Cytotoxicity was assessed using Cytotoxicity Detection Kit according to manufacture's instruction (Roche, Germany). In brief, BNL CL. $2\left(2 \times 10^{5}\right.$ cells $\left./ \mathrm{ml}\right)$ was treated with TAA (0$10000 \mu \mathrm{M}$ ) or $0.5 \%$ DMSO (as vehicle control) and was incubated for 6 or $24 \mathrm{~h}$, and supernatant was mixed with dye solution and catalyst for $30 \mathrm{~min}$. The absorbance at $490 \mathrm{~nm}$ of the solution was measured using a spectrophotometer (Benchmark Plus ${ }^{\mathrm{TM}}$, Bio-Rad Laboratories, Hercules, CA).

\section{RNA isolation and Microarray gene expression profiling}

Total RNAs were extracted for gene expression analysis using the RNeasy Mini kit (Qiagene, Valencia, CA). The yield of RNA was determined spectrophotometrically by measuring the optical density at $260 \mathrm{~nm}$. Total mRNA was converted into double-stranded cDNA using a Chemiluminescent RT-IVT labeling Kit (Applied Biosystems) and an oligo(dT) $)_{24}$ primer. Digoxigenin-labeled cRNA was generated from the doublestranded cDNA using a Chemiluminescent RT-IVT labeling kit. Labeled cRNA was purified using cRNA purification kit 
(Applied Biosystems). The quality and quantity of RNA and cRNA was evaluated using spectrometry and Agilent 2100 Bioanalyzer (Agilent Technologies, Palo Alto, CA).

Each cRNA sample was fragmented by incubation for 30 $\min$ at $60^{\circ} \mathrm{C}$ in fragmentation buffer. The Mouse Genome Survey Microarray gene chip (Applied Biosystems) was hybridized with the fragmented digoxigenin-labeled cRNAs at $55^{\circ} \mathrm{C}$ for $16 \mathrm{~h}$ and then washed. After washing procedure, the chemiluminescent detection, image acquisition and analysis were performed using the Chemiluminescent Detection Kit and Applied Biosystems 1700 Chemiluminescent Microarray Analyzer following the manufacturer's protocols. The chemiluminescent signals from the scanned images were quantified, corrected for background, and spot- and spatially-normalized using the 1700 Chemiluminescent Microarray Analyzer (Applied Biosystems). Microarray analyses were performed for each RNA sample (3 samples/ group).

\section{Data analysis}

For comparison of gene expression profiles, control, vehicle control, 20 and $200 \mathrm{mg} / \mathrm{kg}$ TAA (in vivo), and control, 0 (vehicle control), and 1000 and $10000 \mu \mathrm{M}$ TAA (in vitro) were tested. Two time points for cell harvest of 6 and $24 \mathrm{~h}$ after the treatment were chosen to investigate the time-relating pattern in animals or cells exposed to TAA. Data were analyzed from three independent experiments with samples at 6 and $24 \mathrm{~h}$ after TAA treatment in mice and cell line.

Gene expression data from microarray were input to GenPlex (Istech Co. Ltd., Korea). The signal log ratio values, which represent ratios of hybridization signals between control and treated cells, were calculated after quantile normalization. Significantly altered genes induced by TAA were extracted by One-Way ANOVA $(\mathrm{p}<0.05)$.

$K$-means clustering was performed to identify genes that have a similar differential expression profile across conditions using AVADIS (Strand Life Sciences, Redwood city, CA). Pathway analyses were conducted using DAVID (The Database for Annotation, Visualization and Integrated Discovery) (http://david.abcc.ncifcrf.gov/) and the PANTHER (Protein ANalysis THrough Evolutionary Relationships) (http://www. pantherdb.org/). The extracted genes were categorized based on location, cellular components, and reported or suggested biochemical, biologic, and molecular functions.

\section{Statistical analysis}

Statistical analyses for body weights, liver weights and serum biochemical parameters were performed with the TukeyKramer method using the JMP program (SAS Institute, Cary, NC). For all comparisons, probability values less than $5 \%(\mathrm{p}<$ 0.05 ) were considered to be statistically significant.

\section{RESULTS}

\section{Body and liver weight in mice}

During experiment, there was no death, and were no differences of body weights and absolute and relative liver weights between control and TAA-treated groups (data not shown).

\section{Histopathological examination of liver in mice}

In high dose TAA treatment group, there were severe centrilobular necrosis and hemorrhage at $24 \mathrm{~h}$ after treatment (Fig. 1). However, there was no histopatholgical change at $6 \mathrm{~h}$ in low and high dose and at $24 \mathrm{~h}$ in low dose treatment of TAA (data not shown).

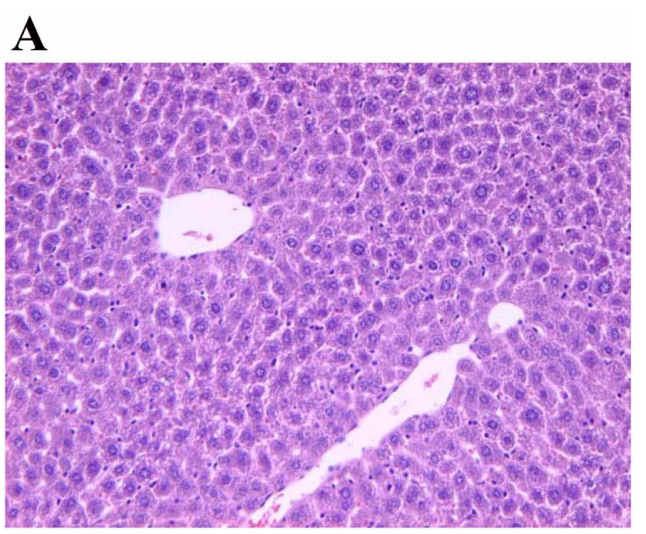

B

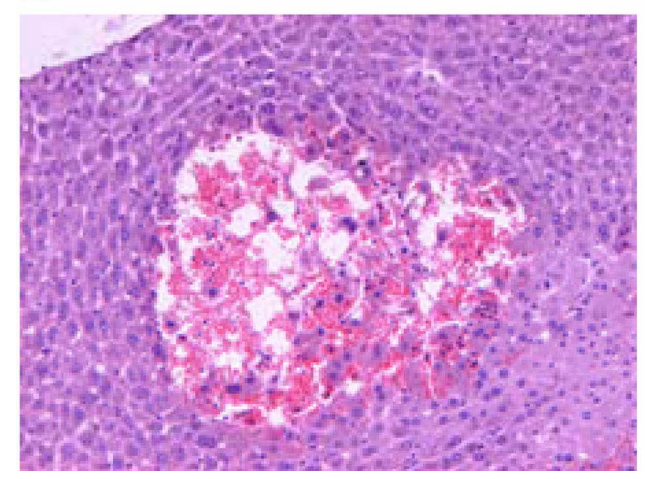

Fig. 1. Histopathological findings of livers of mice. Mice were sacrificed at $24 \mathrm{~h}$ after the treatment as following treatment. A: control; B: TAA $200 \mathrm{mg} / \mathrm{kg}$ 


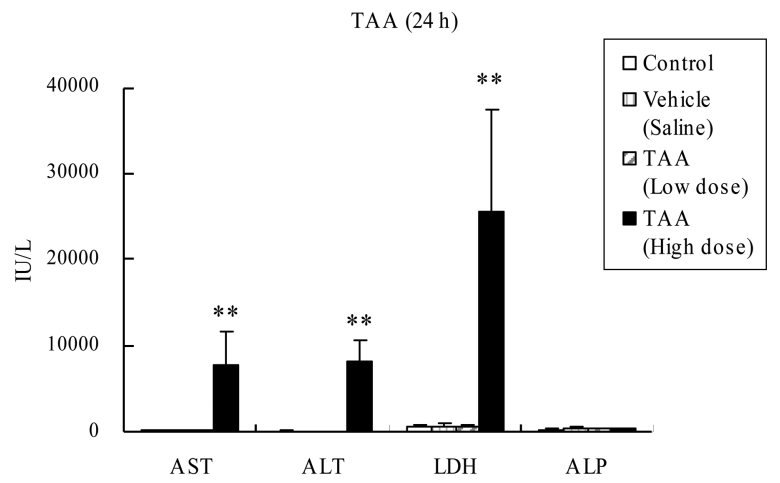

Fig. 2. Changes of aspartate aminotransferase (AST), alanine aminotransferase (ALT), lactate dehydrogenase (LDH), alkaline phosphatase (ALP) in serum of TAA-treated mice. Blood samples are collected at hours 6 and 24 after administration. Data are expressed as mean \pm SD from three or four mice. ${ }^{* * *}$ Significantly different from control group $(\mathrm{p}<0.05, \mathrm{p}<0.01$, respectively)

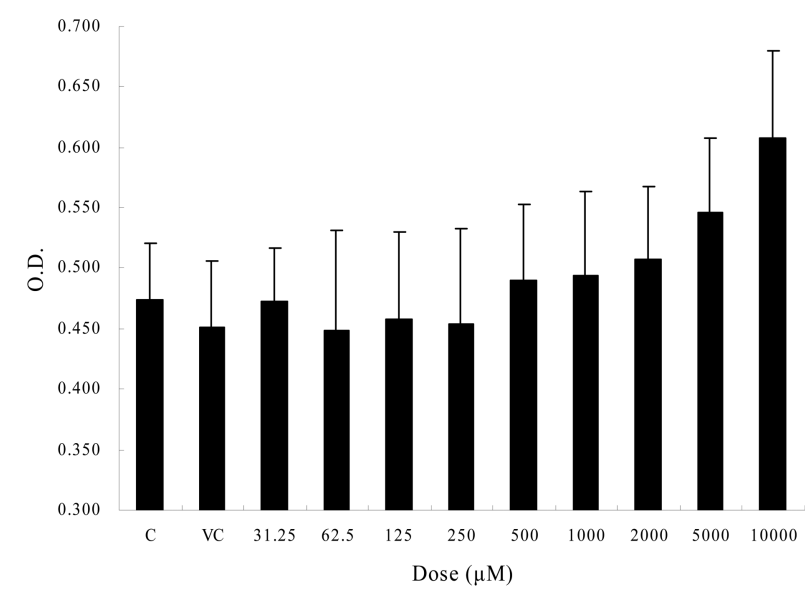

Fig. 3. LDH assay in TAA-treated mouse cell line. Samples are collected at $24 \mathrm{~h}$ after TAA treatment. Data are expressed as mean \pm SD.

\section{Serum biochemistry in mice}

Data for serum biochemistry are shown in Fig. 2. There were significant increases of AST, ALT and LDH in high dose treatment of TAA at $24 \mathrm{~h}(\mathrm{p}<0.01)$. There were no alterations of these parameters at $6 \mathrm{~h}$ after TAA treatment (data not shown).

\section{Cytotoxicity and morphological examination on hepatic cells, BNL CL.2}

In vitro toxicity test showed that TAA treatment induced cellular toxicity over $5000 \mu \mathrm{M}$ (TAA) at $24 \mathrm{~h}$ after TAA treatment (Fig. 3). We set a high dose as $10000 \mu \mathrm{M}$ as apparent cellular toxicity-inducing dose, and one-tenth dose as low dose as not showing apparent cellular toxicity. Morphological

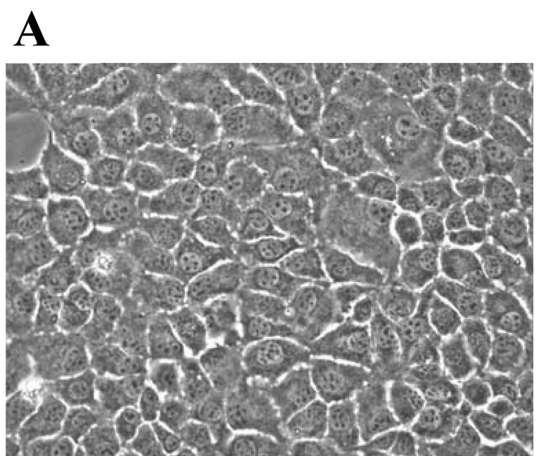

\section{B}

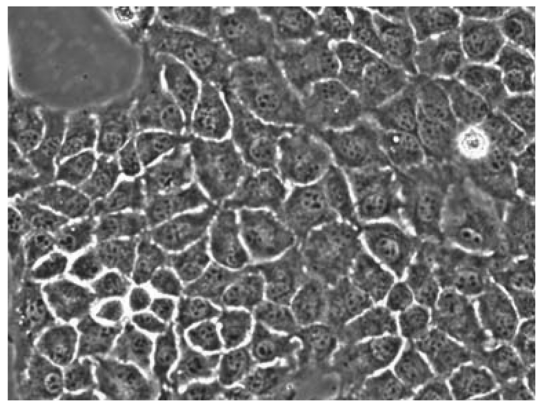

C

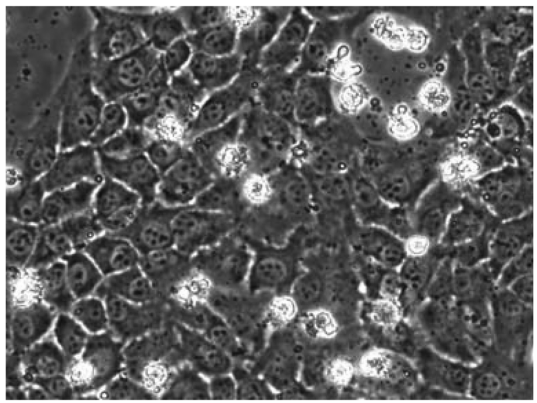

Fig. 4. Morphological aspect of mouse hepatic cell line, BNL CL.2. Cells were treated with following materials and examined at $24 \mathrm{~h}$ after the treatment. A: control; B: vehicle; C: TAA $10000 \mu \mathrm{M}$.

examination of chemical-treated cell lines, cellular toxicity was evident at $24 \mathrm{~h}$ after treatment (Fig. 4).

\section{Microarray analysis of gene expression patterns in BNL CL.2}

Global gene expression showing a significance over 0.05 by One-Way ANOVA showed that there were 677 differentially expressed genes (in vivo) and 1973 genes (in vitro) at $6 \mathrm{~h}$ and 1583 (in vivo) and 2217 (in vitro) at 24 h by TAA treatment, and there were commonly altered genes of 213 and 516 at 6 and $24 \mathrm{~h}$, respectively, between in vivo and in vitro. By timedependent analysis, numbers of commonly up- or down-regu- 
Table I. Commonly altered genes between in vivo and in vitro caused by TAA treatment

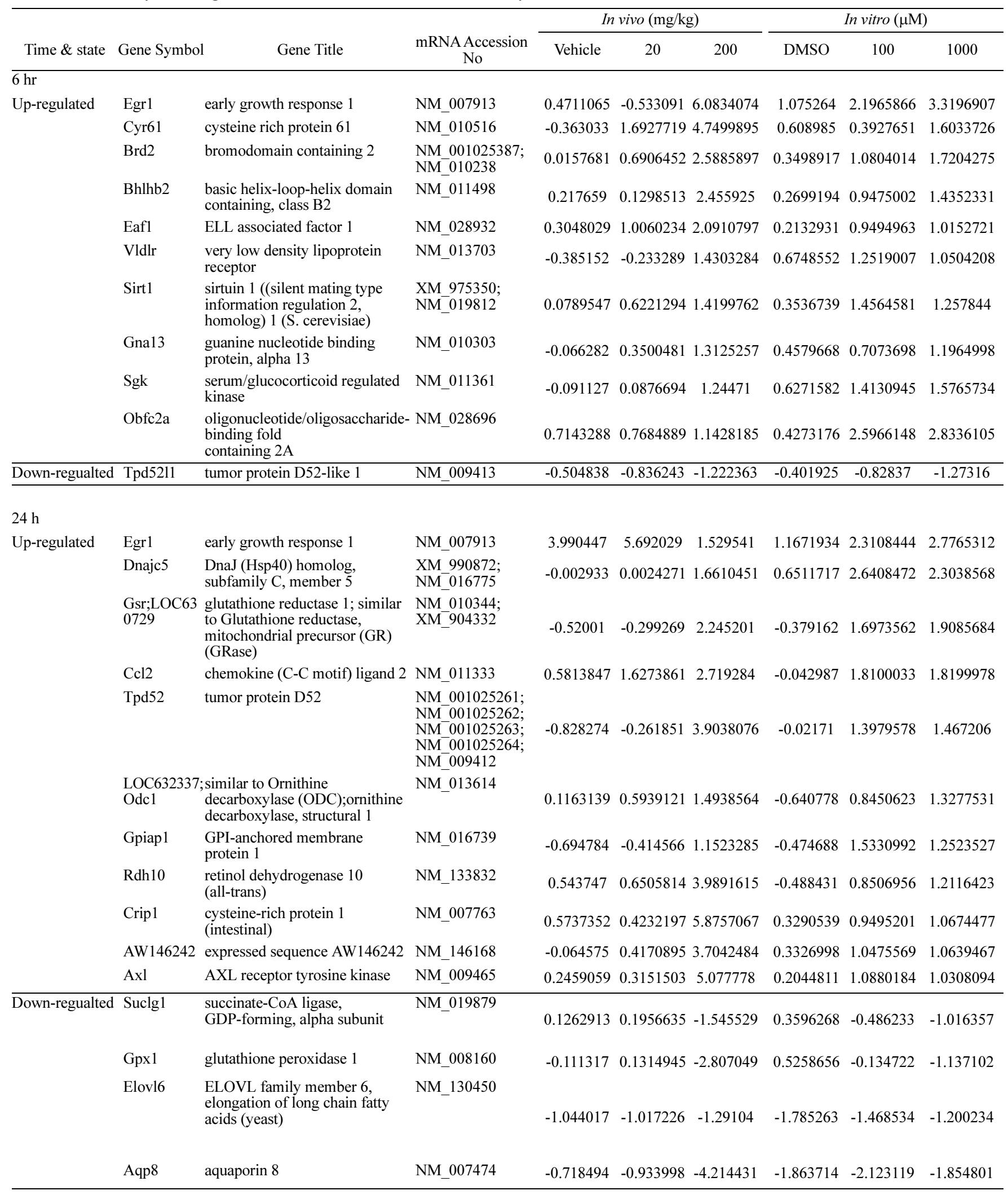


lated genes between in vivo and in vitro caused by TAA treatment were ten and one at $6 \mathrm{~h}$ and eleven and four at $24 \mathrm{~h}$, respectively (Table I).

Hierarchical analysis showed that there were similar patterns between in vivo and in vitro at $6 \mathrm{~h}$ after treatment. However, at $24 \mathrm{~h}$, there was a cluster showing alteration at low dose as well as high dose treatment in in vitro system (Fig. 5). $k$-means clustering analysis showed there were some clusters showing alteration at 6 and $24 \mathrm{~h}$ after high dose as well as low dose treatment of TAA (Fig. 6). These clusters contained several genes such as mitogen activated protein kinase 14, tumor necrosis factor, alpha-induced protein 3, dead box polypeptide 1, thioredoxin reductase 1, cyclin G2. PCA analysis showed groups of TAA treatment were located at a different position compared to control group (Fig. 7). High dose treatment group represented a clear distinction at $6 \mathrm{~h}$ both in vivo and in vitro system. On the while, in in vitro system at $24 \mathrm{~h}$, low dose and high dose groups showed closed location. Pathway analysis for differentially expressed genes by DAVID Bioinformatic Resources (NIAID/NIH) identified that there were 11 (in vivo) and 22 (in vitro) pathways by TAA treatment, and identified several common pathways between in vivo and in vitro system such as glutathione metabolism, bile acid biosynthesis, nitrogen metabolism, butanoate metabolism for TAA-induced hepatotoxicty (Table II).

\section{DISCUSSION}

Hierarchical clustering analysis showed that there were
A

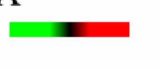

$\begin{array}{llll}1 & 2 & 3 & 4\end{array}$

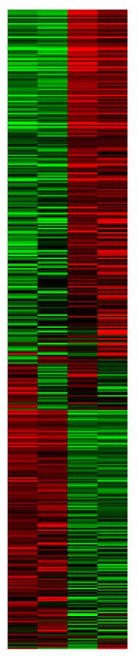

B

$\begin{array}{llll}1 & 2 & 3 & 4\end{array}$

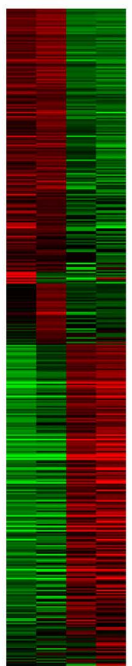

C

$\begin{array}{llll}1 & 2 & 3 & 4\end{array}$

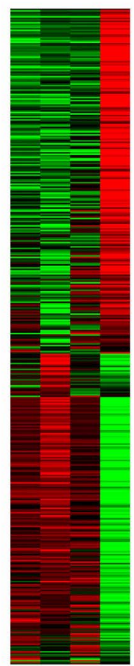

$\mathrm{D}$

$\begin{array}{llll}1 & 2 & 3 & 4\end{array}$

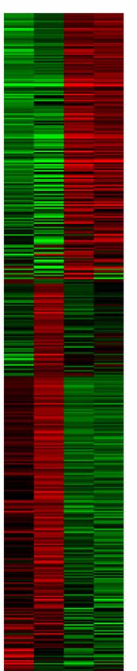

Fig. 5. Hierarchical clustering analysis of genes altered by TAA treatment. A: in vivo at $6 \mathrm{~h}$; B: in vitro at $6 \mathrm{~h}$; C: in vivo at $24 \mathrm{~h}$; D: in vitro at $24 \mathrm{~h}$; Lane 1: control; Lane 2: Vehicle; Lane 3: Low dose treatment; Lane 4: High dose treatment.

generally similar patterns between in vivo and in vitro. However, in vitro, there were several clusters showing simultaneous alteration at both 6 and $24 \mathrm{~h}$ in low and high dose group of TAA treatment by hierarchical clustering and $k$-means analysis. PCA analysis also showed that low dose and high dose groups showed closed location at $24 \mathrm{~h}$ in in vitro system,
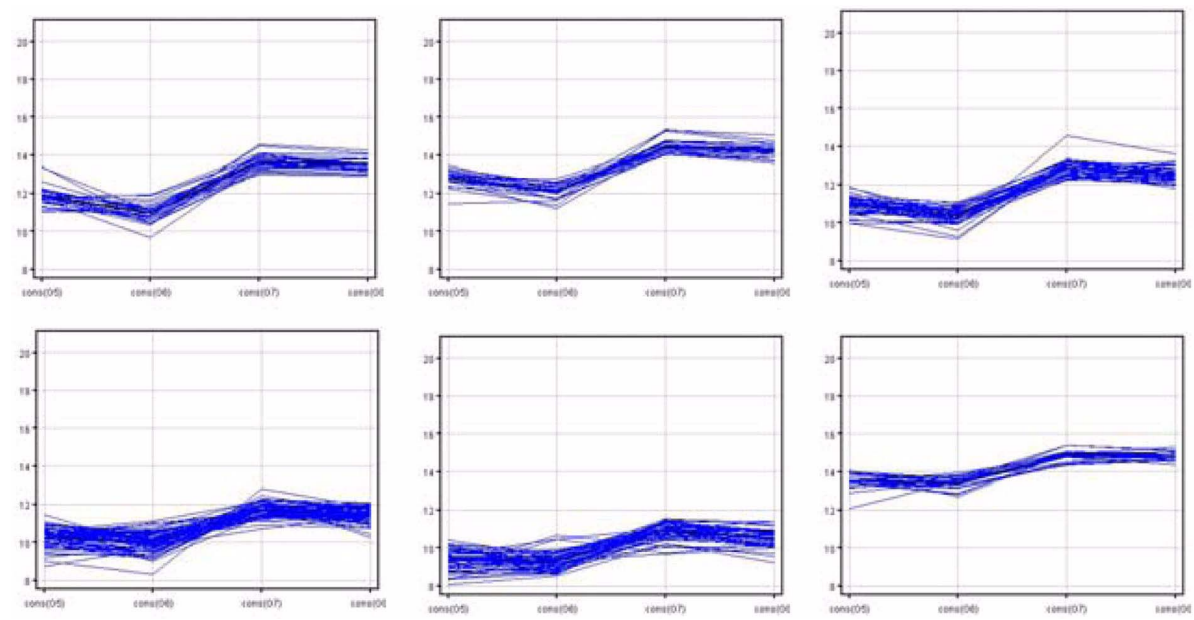

Fig. 6. $k$-means clustering analysis. It represents there are some clusters showing alteration both low and high dose treatment of TAA in in vitro. 


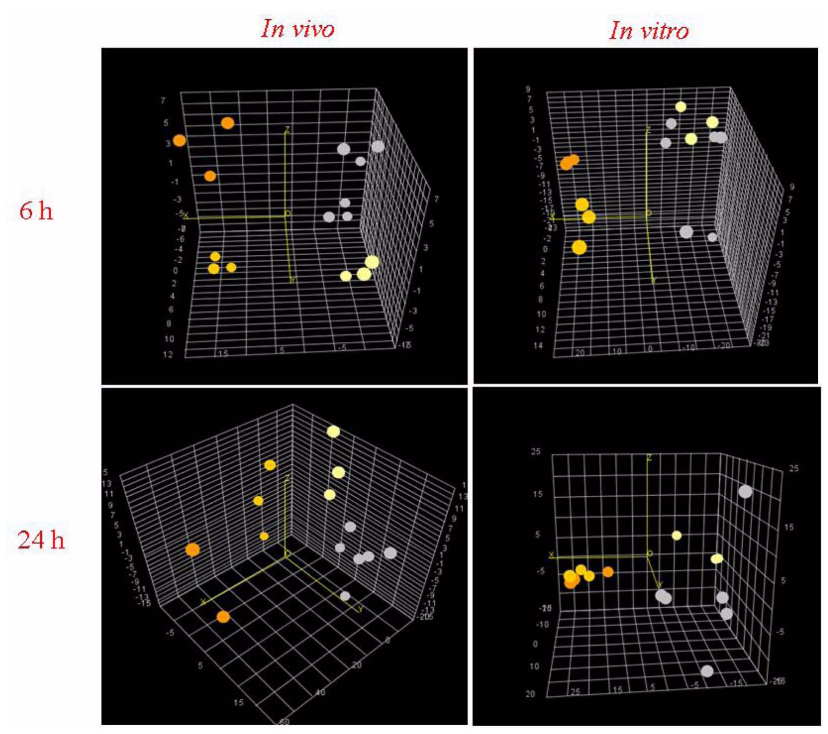

Fig. 7. Principal Component Analysis (PCA) for altered genes by TAA treatment. In vivo at 6 and 24 h: Control as grey; Vehicle as lemon color; Low dose treatment as deep yellow; High dose treatment as orange color; In vitro at 6 and 24h: Control as grey; Vehicle as lemon color; Low dose treatment as deep yellow; High dose treatment as orange color

representing higher sensitivity to low dose treatment of TAAinduced toxicity than in vivo. Even though there were no toxicological responses at $6 \mathrm{~h}$ after TAA treatment, our microarray data represents in vitro may detect toxic response more sensitive way, even at low dose. And our PCA data provided a clear distinction between control or vehicle treatment group and toxicant-treated groups. It suggests that gene expression data can be used to discern different hepatotoxic agents and toxicity endpoints as shown in a previous report (Huang et al. 2004).

Pathway analysis for differentially expressed genes identified that there were 11 (in vivo) and 22 (in vitro) pathways by TAA treatment, representing in vitro system has more biological pathways than in vivo system. It seems there may be more defense mechanism existed in in vivo more than in vitro. And our experiments also showed there were many gene alterations relating to oxidative stress both in vivo and in vitro. As pathway analysis represented that there were several common pathways between in vivo and in vitro system, it suggests that it may be feasible to extract common biomarkers by comparing the pathways from in vivo and in vitro genomic profiles. Statistical analysis of global gene expression identified that there were 677 genes (in vivo) and 1913 genes (in vitro) at $6 \mathrm{~h}$ and 1583 and 2217 at $24 \mathrm{~h}$ caused by TAA. It represented more numbers of genes found in in vitro than in vivo. Our
Table II. Pathway analysis altered by TAA treatment (KEGG)

\begin{tabular}{|c|c|}
\hline In vivo pathway & $\begin{array}{l}\text { Number of } \\
\text { related genes }\end{array}$ \\
\hline GLUTATHIONE METABOLISM & 5 \\
\hline BILE ACID BIOSYNTHESIS & 4 \\
\hline NITROGEN METABOLISM & 5 \\
\hline BUTANOATE METABOLISM & 7 \\
\hline ASCORBATE AND ALDARATE METABOLISM & 6 \\
\hline FRUCTOSE AND MANNOSE METABOLISM & 7 \\
\hline GALACTOSE METABOLISM & 7 \\
\hline TETRACHLOROETHENE DEGRADATION & 4 \\
\hline BISPHENOL A DEGRADATION & 4 \\
\hline NUCLEOTIDE SUGARS METABOLISM & 4 \\
\hline LINOLEIC ACID METABOLISM & 7 \\
\hline \multicolumn{2}{|l|}{ In vitro pathway } \\
\hline GLUTATHIONE METABOLISM & 11 \\
\hline BILE ACID BIOSYNTHESIS & 6 \\
\hline NITROGEN METABOLISM & 4 \\
\hline BUTANOATE METABOLISM & 10 \\
\hline ASCORBATE AND ALDARATE METABOLISM & 4 \\
\hline FRUCTOSE AND MANNOSE METABOLISM & 11 \\
\hline GALACTOSE METABOLISM & 9 \\
\hline TETRACHLOROETHENE DEGRADATION & 3 \\
\hline BISPHENOL A DEGRADATION & 5 \\
\hline OXIDATIVE PHOSPHORYLATION & 30 \\
\hline CELL CYCLE & 16 \\
\hline TIGHT JUNCTION & 25 \\
\hline RNA POLYMERASE & 6 \\
\hline GLUTAMATE METABOLISM & 8 \\
\hline $\begin{array}{l}\text { D-GLUTAMINE AND D-GLUTAMATE } \\
\text { METABOLISM }\end{array}$ & 3 \\
\hline PYRIMIDINE METABOLISM & 13 \\
\hline LYSINE DEGRADATION & 10 \\
\hline $\begin{array}{l}\text { GLYCINE, SERINE AND THREONINE } \\
\text { METABOLISM }\end{array}$ & 9 \\
\hline N-GLYCAN DEGRADATION & 6 \\
\hline LIMONENE AND PINENE DEGRADATION & 5 \\
\hline $\begin{array}{l}\text { PORPHYRIN AND CHLOROPHYLL } \\
\text { METABOLISM }\end{array}$ & 5 \\
\hline B CELL RECEPTOR SIGNALING PATHWAY & 10 \\
\hline
\end{tabular}

attempt to identify commonly altered genes between in vivo and in vitro showed oxidative stress and lipid metabolism related genes were involved in TAA-induced toxicity. TAA is generally thought to be bioactivated by CYP and/or flavin-containing monooxygenase (FMO) systems to sulfine (sulfoxide) and sulfene (sulfone) metabolites (Hunter et al. 1977; Porter et al. 1979). Phenobarbital pretreatment potentiated TAA toxicity, parallel to the induction of CYP and FMO (Hunter et al. 1977; Zaragoza et al. 2000). Among metabolizing enzymes, CYP2E1 
is associated with elevated hepatotoxicity (Nieto et al. 1999; Wang et al. 2005) and increases TAA-induced liver injury in diabetic (Wang et al. 2000) or diet-restricted rats (Ramaiah et al. 2001). And CYP2E1-null mice show no toxicity when treated with TAA (Kang, J.S. et al., 2007), suggesting that CYP2E1 is the principal enzyme responsible for the metabolic conversion of this chemical to their active hepatotoxic metabolite. However, our experiment showed that the expression of CYP2E1 was not picked up as shown in previous report (Minami et al. 2005).

Generally, it seems that there were similar pattern between in vivo and in vitro in our experiments. However, there were somewhat discrepancies of expression pattern by time. In TAAtreated mice, there were evident changes of serum biochemical parameters at $24 \mathrm{~h}$, associated with manifest histopathological lesions at the same time. It was reported that there were good correlation between the histopathology, clinical chemistry, and gene expression profiles induced by hepatotoxicants (Waring et al. 2001b). However, our data suggest there may be timedependent alterations of genes. Therefore, it is very important to set a relevant exposure time for toxicants, with an awareness of relations between early time and later time profiles. As there has been a trend recently in focusing on toxicogenomic profiles after short-term treatment of some chemicals in vivo (Bulera et al. 2001; Ellinger-Ziegelbauer et al. 2004; Michel et al. 2003), further studies are thus warranted to analyze detailed alterations from early to late stages of hepatoxic process, so that any hepatopreventive strategy can be based on a firm foundation.

As expected, there was not an exact correlation between two systems. It should be reminded that liver tissue and primary cells express different suites of genes and it suggests they have fundamental differences in their cell physiology, and also indicating that care must be taken in extrapolating from primary cells to whole animal organ toxicity effects (Perkins et al. 2006). Further multidimensional data set for liver toxicity provide an informatics challenge requiring appropriate computational methods for integrating various toxicological data into profiles and models predicting toxicity (Dix et al. 2007).

Taken together, our results suggest it may be feasible to develop toxicogenomics biomarkers by comparing in vivo and in vitro genomic profiles specific to hepatotoxic chemical(s) for application to prediction of liver toxicity.

\section{ACKNOWLEDGEMENTS}

This research was supported by a research grant,
06131 Omics401 (2006) to Dr. Sue Nie Park from the National Institute of Toxicological Research, Korea Food and Drug Administration of Korea.

\section{REFERENCES}

Boverhof, D. R. and Zacharewski, T. R. (2006). Toxicogenomics in risk assessment: applications and needs. Toxicol. Sci. 89, 352-360.

Bulera, S. J., Eddy, S. M., Ferguson, E., Jatkoe, T. A., Reindel, J. F., Bleavins, M. R. and De La Iglesia, F. A. (2001). RNA expression in the early characterization of hepatotoxicants in Wistar rats by high-density DNA microarrays. Hepatology 33, 1239-1258.

Corvi, R., Ahr, H. J., Albertini, S., Blakey, D. H., Clerici, L., Coecke, S., Douglas, G. R., Gribaldo, L., Groten, J. P., Haase, B., Hamernik, K., Hartung, T., Inoue, T., Indans, I., Maurici, D., Orphanides, G., Rembges, D., Sansone, S. A., Snape, J. R., Toda, E., Tong, W., van Delft, J. H., Weis, B. and Schechtman, L. M. (2006). Meeting report: Validation of toxicogenomicsbased test systems: ECVAM-ICCVAM/NICEATM considerations for regulatory use. Environ. Health Perspect. 114, 420429.

Dix, D. J., Houck, K. A., Martin, M. T., Richard, A. M., Setzer, R. W. and Kavlock, R. J. (2007). The ToxCast program for prioritizing toxicity testing of environmental chemicals. Toxicol. Sci. 95, 5-12.

Ellinger-Ziegelbauer, H., Stuart, B., Wahle, B., Bomann, W. and Ahr, H. J. (2004). Characteristic expression profiles induced by genotoxic carcinogens in rat liver. Toxicol. Sci. 77, 19-34.

Huang, Q., Jin, X., Gaillard, E. T., Knight, B. L., Pack, F. D., Stoltz, J. H., Jayadev, S. and Blanchard, K. T. (2004). Gene expression profiling reveals multiple toxicity endpoints induced by hepatotoxicants. Mutat. Res. 549, 147-168.

Hunter, A. L., Holscher, M. A. and Neal, R. A. (1977). Thioacetamide-induced hepatic necrosis. I. Involvement of the mixedfunction oxidase enzyme system. J. Pharmacol. Exp. Ther. 200, 439-448.

James, L. P., Mayeux, P. R. and Hinson, J. A. (2003). Acetaminophen-induced hepatotoxicity. Drug. Metab. Dispos. 31, 1499-1506.

Kang, J. S., Morimura, K., Salim, E. I., Wanibuchi, H., Yamaguchi, S. and Fukushima, S. (2005). Persistence of liver cirrhosis in association with proliferation of nonparenchymal cells and altered location of alpha-smooth muscle actin-positive cells. Toxicol. Pathol. 33, 329-335.

Kang, J.S., Wanibuchi, H., Wongpoomchai, R., Chusiri, Y., Gonzalez, F. J., Fukushima, S. (2007). Role of CYP2E1 in hepatotoxicity induced by thioacetamide. Toxicol. Appl. Pharmacol. In Press.

Leighton, J. K., Brown, P., Ellis, A., Harlow, P., Harrouk, W., Pine, P. S., Robison, T., Rosario, L. and Thompson, K. (2006). Workgroup report: Review of genomics data based on experience with mock submissions--view of the CDER Pharmacology Toxicology Nonclinical Pharmacogenomics Subcommittee. Environ. Health Perspect. 114, 573-578.

Li, X., Benjamin, I. S. and Alexander, B. (2002). Reproducible production of thioacetamide-induced macronodular cirrhosis in the rat with no mortality. J. Hepatol. 36, 488-493.

Michel, C., Desdouets, C., Sacre-Salem, B., Gautier, J. C., Roberts, R. and Boitier, E. (2003). Liver gene expression profiles 
of rats treated with clofibric acid: comparison of whole liver and laser capture microdissected liver. Am. J. Pathol. 163, 2191-2199.

Minami, K., Saito, T., Narahara, M., Tomita, H., Kato, H., Sugiyama, H., Katoh, M., Nakajima, M. and Yokoi, T. (2005). Relationship between hepatic gene expression profiles and hepatotoxicity in five typical hepatotoxicant-administered rats. Toxicol. Sci. 87, 296-305.

Muller, A., Machnik, F., Zimmermann, T. and Schubert, H. (1988). Thioacetamide-induced cirrhosis-like liver lesions in rats--usefulness and reliability of this animal model. Exp. Pathol. 34, 229-236.

Nieto, N., Friedman, S. L., Greenwel, P. and Cederbaum, A. I. (1999). CYP2E1-mediated oxidative stress induces collagen type I expression in rat hepatic stellate cells. Hepatology 30, 987-996.

Pennie, W., Pettit, S. D. and Lord, P. G. (2004). Toxicogenomics in risk assessment: an overview of an HESI collaborative research program. Environ. Health Perspect. 112, 417-419.

Perkins, E. J., Bao, W., Guan, X., Ang, C. Y., Wolfinger, R. D., Chu, T. M., Meyer, S. A. and Inouye, L. S. (2006). Comparison of transcriptional responses in liver tissue and primary hepatocyte cell cultures after exposure to hexahydro-1, 3, 5trinitro-1, 3, 5-triazine. BMC Bioinformatics 7 Suppl 4, S22.

Porter, W. R., Gudzinowicz, M. J. and Neal, R. A. (1979). Thioacetamide-induced hepatic necrosis. II. Pharmacokinetics of thioacetamide and thioacetamide-S-oxide in the rat. J. Pharma- col. Exp. Ther 208, 386-391.

Ramaiah, S. K., Apte, U. and Mehendale, H. M. (2001). Cytochrome P4502E1 induction increases thioacetamide liver injury in diet-restricted rats. Drug Metab. Dispos. 29, 1088-1095.

Wang, T., Shankar, K., Ronis, M. J. and Mehendale, H. M. (2000). Potentiation of thioacetamide liver injury in diabetic rats is due to induced CYP2E1. J. Pharmacol. Exp. Ther. 294, 473-479.

Wang, X., Lu, Y. and Cederbaum, A. I. (2005). Induction of cytochrome P450 2E1 increases hepatotoxicity caused by Fas agonistic Jo2 antibody in mice. Hepatology 42, 400-410.

Waring, J. F., Ciurlionis, R., Jolly, R. A., Heindel, M. and Ulrich, R. G. (2001a). Microarray analysis of hepatotoxins in vitro reveals a correlation between gene expression profiles and mechanisms of toxicity. Toxicol. Lett. 120, 359-368.

Waring, J. F., Jolly, R. A., Ciurlionis, R., Lum, P. Y., Praestgaard, J. T., Morfitt, D. C., Buratto, B., Roberts, C., Schadt, E. and Ulrich, R. G. (2001b). Clustering of hepatotoxins based on mechanism of toxicity using gene expression profiles. Toxicol. Appl. Pharmacol. 175, 28-42.

Waters, M. D. and Fostel, J. M. (2004). Toxicogenomics and systems toxicology: aims and prospects. Nat. Rev. Genet. 5, 936948.

Zaragoza, A., Andres, D., Sarrion, D. and Cascales, M. (2000). Potentiation of thioacetamide hepatotoxicity by phenobarbital pretreatment in rats. Inducibility of FAD monooxygenase system and age effect. Chem. Biol. Interact. 124, 87-101. 